\title{
Syntrichia norvegica Shoots Exhibit a Complex Inducible Response to Desiccation: separating the effects of Rate of Drying and Water Content
}

\begin{tabular}{|r|l|}
\hline Journal: & Botany \\
\hline Manuscript ID & cjb-2016-0263.R1 \\
\hline Manuscript Type: & Article \\
\hline Date Submitted by the Author: & 12-Nov-2016 \\
\hline Complete List of Authors: & $\begin{array}{l}\text { Stark, Lloyd; University of Nevada, } \\
\text { Greenwood, Joshua; University of Nevada } \\
\text { Slate, Mandy; University of Montana } \\
\text { Brinda, John; Missouri Botanical Garden }\end{array}$ \\
\hline Keyword: & $\begin{array}{l}\text { constitutive, ectohydry, chlorophyll fluorescence, regeneration, } \\
\text { suprasaturation }\end{array}$ \\
\hline & \\
\hline
\end{tabular}

\section{SCHOLARONE \\ Manuscripts}




\section{Syntrichia norvegica Shoots Exhibit a Complex Inducible Response} to Desiccation: separating the effects of Rate of Drying and Water

\section{Content}

Lloyd R. Stark ${ }^{1,4}$, Joshua L. Greenwood ${ }^{1}$, Mandy L. Slate ${ }^{2}$, and John C. Brinda ${ }^{3}$

${ }^{1}$ School of Life Sciences, University of Nevada, 4505 Maryland Parkway, Las Vegas, Nevada 89154-4004, USA, email LRS@UNLV.nevada.edu, email greenw33@unlv.nevada.edu

2 Division of Biological Sciences, University of Montana, Missoula, Montana 59812, USA, email slatemandy@gmail.com

${ }^{3}$ Missouri Botanical Garden, P.O. Box 299, St. Louis, Missouri 631660299, USA, email john.brinda@mobot.org

running head: Desiccation Tolerance in Syntrichia norvegica

${ }^{4}$ Corresponding author: Lloyd Stark, E-mail: LRS@UNLV.nevada.edu, Tele 702-895-3119, FAX 702-895-3956 
Stark et al. - Desiccation Tolerance in Syntrichia norvegica page 2

\begin{abstract}
Plants in the moss genus Syntrichia are considered to be constitutively desiccation tolerant (DT) - able to tolerate a rapid drying event without incurring significant damage upon rehydration. However, few workers have considered the separate effects of rate of drying and water content and incorporated fully dehardened (to DT) plants in the experiments. Plants of S. norvegica were cultured under conditions of suprasaturation and adult shoots were exposed to a range of drying rates and equilibrating relative humidities, rehydrated and assessed for chlorophyll fluorescence and regeneration potential. Adult shoots exhibited severe damage across all drying rates when equilibrated at RHs $<30 \%$. However, an inducible response to desiccation was present across all water contents as the rate of drying was extended from 0 to $4 \mathrm{~d}$. The least desiccation damage occurred at longer drying times and higher water contents $(8 \mathrm{~d}$ at $75 \% \mathrm{RH})$. A constitutive phenotype for DT was not strictly evident in S. norvegica. Rather, we observed an incomplete pattern of environmentally inducible DT coupled with heavy shoot damage at lower water contents. Rate of drying and equilibrating RH clearly interact in producing the pattern and strategy of DT for this species.
\end{abstract}

Key words: constitutive, ectohydry, chlorophyll fluorescence, regeneration, suprasaturation, mosses 
Stark et al. - Desiccation Tolerance in Syntrichia norvegica page 3

\section{INTRODUCTION}

Desiccation tolerance (DT) in bryophytes is a reversible plastic trait (Gabriel 2005), i.e., a phenotype that is induced in a drying environment (hardening or acclimation) protects the plant both upon immediate rehydration and also against a future rapid drying event, but which is lost if the plants remain hydrated for more than a few days (dehardening to DT). Although DT is normally conceived as having two potential ecological strategies (constitutive and inducible DT), each species, plant structure, or life history stage is likely to exhibit a tolerance strategy along a gradient of inducibility (Stark and Brinda 2015). Further, such a strategy of surviving desiccation is likely to vary with the conditions attending drying, namely the rate at which plants are dried and the water content at which the plants are equilibrated.

The moss genus Syntrichia has been a historical focus for studies on the desiccation tolerance of plants, with the species $S$. ruralis and S. caninervis (especially the former) receiving the most attention (see references in Stark et al. 2014). The scientific consensus regarding the response strategy for tolerating desiccation in Syntrichia species points toward a system of constitutive protection (CDT) coupled with rehydration-induced repair (Proctor et al. 2007). This consensus of CDT protection is based on unchanging levels of dehydrins throughout a drying/rehydrating cycle (Bewley 1995); the ability of photocenters to reactivate in minutes or very quickly upon rehydration (Wood 2007; Zhang et al. 2011); the sequestration of desiccation-active transcripts during drying that immediately undergo translation upon rehydration (Wood \& Oliver 1999); and the inabilility to deharden to DT (Stark et al. 2012). 
Stark et al. - Desiccation Tolerance in Syntrichia norvegica page 4

As presented by Green et al. (2011) and Brinda et al. (2016), the principal factors of desiccation can be considered as (1) rate of drying $(R o D)$, (2) equilibrating relative humidity (RHeq, which equates to a specific water content, WC), and (3) duration dry (how long the plants continuously experience the desiccated state). Historically, the factors $R o D$ and $R H e q$ are considered together as "intensity" of desiccation, and normally comprise the main desiccating treatment used in most experiments on bryophyte DT. Potential variation in the phenotype of DT may be lost when $\mathrm{RoD}$ and $\mathrm{RHeq}$ are combined as "intensity" of DT, especially if each factor has a unique effect or if the factors interact. Thus an important factor in understanding DT in Syntrichia remains unresolved: the relationship between the rate at which plants are desiccated and the equilibrating relative humidity $(\mathrm{RH})$ experienced by the plants, the latter of which determines water content (WC). Separating these two factors may assist in understanding the relative effects of each factor of DT to the biological response, recovery, adaptation, and evolutionary trajectories of each species.

Traditionally a plant is considered to be DT if it can survive equilibration with air at $\sim 50 \%$ RH (Alpert 2006). At approximately 50\% RH plants have desiccated to a point that they retain only about $10 \%$ of their original water content (Alpert 2005). Intracellular vitrification of the cytoplasm is predicted to occur between $10 \%$ and $30 \%$ of water content (Wolfe \& Bryand 1999; Hoekstra et al. 2001) and is a part of the desiccation tolerance program plants employ to minimize structural damage during water loss. There are valid reasons, however, for expanding the definition of DT to tolerances above $50 \%$ RH. First, most bryophyte species reach subturgor (slightly below full turgor) at equilibrating RHs of $\sim 98 \%$ (water potentials $<\sim-2.0 \mathrm{MPa}$, Proctor 2008), and second, during a dry-down the leaves of mosses begin to curl up (contort) and exhibit the 
Stark et al. - Desiccation Tolerance in Syntrichia norvegica page 5

"desiccation morphology" characteristic of the species at $\sim 86 \%$ RH $(\sim-20 \mathrm{MPa})$, and at this point most photosynthetic and metabolic process are markedly reduced (Dilks \& Proctor 1979; Schonbeck \& Bewley 1981; Proctor 2001; Walters et al. 2005; Buda et al. 2013; Brinda et al. 2016 and references therein). Thus there are grounds for including as DT those species that can survive when equilibrated with RHs of up to $85 \%$, even though biological glass formation has not yet occurred.

Bryophytes are poikilohydric, i.e., the plants are unable to regulate internal tissue water content and instead rapidly equilibrate their hydration status to the immediate environment. If external water is absent the plants desiccate, with their tissue weight dependent on the environmental relative humidity $(\mathrm{RH})$. Many bryophytes are able to conduct and even store water externally, a trait known as ectohydry. In species like Syntrichia, external water is stored among shoots within a colony (Rice 2012). Additionally, leaves of many bryophytes strategically separate water storage from gas exchange. Water storage pockets persist in the concave reservoirs of the hydrophilic adaxial leaf surfaces while gas exchange occurs on the lower hydrophobic convex surface of the unistratose leaves (Proctor 2008; Green et al. 2011). Bryophytes must be hydrated in order to photosynthesize but because these plants rely on diffusion for $\mathrm{CO}_{2}$ intake, too much external water has the potential to hinder gas exchange. Thus, this physical separation of water storage and gas exchange allows net photosynthesis to continue longer while water is continually accessed from the reservoir on the upper side of the leaf (figured for Pseudocrossidium crinitum in Rundel and Lange 1980), in many cases without a significant dropoff in net photosynthesis.

We approach the standing hypothesis that Syntrichia species are constitutively desiccation tolerant (incapable of dehardening) by assessing how shoots of S. norvegica, 
Stark et al. - Desiccation Tolerance in Syntrichia norvegica page 6

maintained in a state of suprasaturation (defined as having a relative water content in excess of full turgor; Proctor 2008) that ensures the plants are entirely dehardened to DT, respond to a range of rates of drying and equilibrating relative humidities. The resulting pattern does not fall neatly into the dichotomy of constitutive or inducible DT, or even at a distinct point along a gradient of inducibility, but rather recovery from desiccation in $S$. norvegica depends upon the interacting factors of RoD and RHeq during drying.

\section{MATERIALS AND METHODS}

\section{Species description}

Syntrichia norvegica F. Weber is a locally common species that is widely distributed in the northern hemisphere and also occurs in southern Africa. It is generally a species of higher elevations and/or higher latitudes. The species is characterized by its larger laminal cell size, its brightly colored orange-reddish awns, and the weak dorsal stereid band. The stereid band is a group of thick-walled, fiberlike cells found in the costa (mid-vein) of the leaves of some moss species. In S. norvegica, the stereids are often entirely absent just below the leaf apex making the costa difficult to distinguish from the adjacent lamina.

\section{Culture technique}

Decontamination of Brinda 288 (USA, Nevada, Clark County, Bonanza Peak Trail, Spring Mountains, $36.377961^{\circ} \mathrm{N}, 115.753123^{\circ} \mathrm{W}, 2690.0 \mathrm{~m}$, vouchered at MO, UNLV) was achieved by subculturing shoot apices until the associated protists/fungi/cyanobacteria were not observed. Plants were raised in Petri dishes (inner diameter $=35 \mathrm{~mm})$ containing locally collected, sieved $(355 \mu \mathrm{m})$, dry-sterilized, $\mathrm{pH}-$ neutral sand watered with 30\% Hoaglands solution (Hoagland \& Arnon 1938) under a 
Stark et al. - Desiccation Tolerance in Syntrichia norvegica page 7

12-h photoperiod $\left(20^{\circ} \mathrm{C}\right.$ lighted, $8^{\circ} \mathrm{C}$ darkened) in a plant growth chamber (Percival E30B, Boone, Iowa, USA) with a photon flux density of $\sim 175 \mu \mathrm{mol} \mathrm{m} \mathrm{sec}^{-1}$

photosynthetic active radiation (PAR). When the shoots reached the lid of the Petri dish, the lower dish was transferred to a deeper watch glass, allowing the shoot population to reach at least $15 \mathrm{~mm}$ in length over the course of 3-4 months. Cultures were checked daily and watered with $30 \%$ Hoagland's solution in order to maintain the shoots in a suprasaturated condition (Fig. 1a).

\section{Experimental design}

Shoots were grown under suprasaturating conditions in order to remove any hardening to DT. Adult shoot apices of S. norvegica were dried in glass desiccators over salt solutions equating to equilibrating RHs (RHeq) of 75, 54, 23, and $0 \%$. Within each equilibrating $\mathrm{RH}$, rate of drying $(\mathrm{RoD}$, as the time from full turgor to leaf curling that occurs during a dry-down from $98 \%$ to $\sim 86 \% \mathrm{RH}$ ) was varied from $30 \mathrm{~min}$ to $\sim 200 \mathrm{~h}$.

\section{Water content}

Water content (WC) was calculated on a dry weight (DWt) basis as:

$[($ Experimental $\mathrm{Wt}-\mathrm{DWt}) / \mathrm{DWt}] \times 100$. Groups of 4 shoots were selected, cropped at $8-$ $10 \mathrm{~mm}$ in length, and blotted on a chemical wipe until the external water was mostly absent while the shoots were yet at full turgor. Fresh weight (FW) was taken of individual shoots to the nearest $\mu \mathrm{g}$ using a microbalance (Sartorius M2P, Göttingen, Germany). Shoots were then placed in the appropriate glass desiccator for $48 \mathrm{~h}$ in unlidded Petri dishes with 2 sheets of Whatman \#1 filter paper that were preequilibrated at least $24 \mathrm{~h}$ at the designated RH, which allowed complete equilibration with the desiccator RH. Each shoot was weighed directly from the desiccator (Experimental Wt), then oven-dried at $80^{\circ} \mathrm{C}$ for $3 \mathrm{~d}$ to yield $\mathrm{DWt}$, and re-weighed. For suprasaturation WC (WC of shoots that 
Stark et al. - Desiccation Tolerance in Syntrichia norvegica page 8

are growing in a supersaturated condition), each shoot was cut and lifted directly from the culture and into the weigh dish. For cutting, we used fine forceps and a straight edge, cutting at just above the water level in the culture dish.

\section{Drying treatment}

Shoots of $S$. norvegica that were available (3-5 months old), at least $12 \mathrm{~mm}$ in length, and unbranched, were removed from a culture in groups of four, placed in a drop of sterile water, cleaned and cut to $8-10 \mathrm{~mm}$ in length using a straight edge, and blotted free of visible external water for $\sim 30 \mathrm{sec}$ (or until external water had dissipated while shoots were at full turgor, Fig. 1B) on a chemical wipe. The drying technique employed is derived from Werner et al. (1991) and Pressel and Duckett (2010), as modified in Stark et al. (2013). Immediately upon blotting, the contiguous group of four shoots was transferred into a Petri dish and the Petri dish placed in a glass desiccator containing a saturated salt solution producing atmospheres of $0 \%\left(\mathrm{CaSO}_{4(\mathrm{~s})}\right), 23 \%\left(\mathrm{KCH}_{3} \mathrm{CO}_{2}\right), 54 \%$ $\left(\mathrm{Mg}\left(\mathrm{NO}_{3}\right)_{2}\right)$, or $75 \%(\mathrm{NaCl}) \mathrm{RH}$. Petri dishes were fitted with circular sheets of preequilibrated Whatman \#1 filter paper (using one sheet per $100 \mu \mathrm{L}$ pipetted sterile water) and an iButton (Maxim, San Jose, CA, USA) positioned adjacent to the shoots to record $\mathrm{T}$ and $\mathrm{RH}$ adjacent to the drying shoots. The Petri dish was unlidded within the desiccator for rapid dry-downs (RD) and lidded for slower drying times (SD). All manipulations were carried out in an environmental room set to $20^{\circ} \mathrm{C}, 50 \% \mathrm{RH}$, under continuous low light of $2-4 \mu \mathrm{mol} \mathrm{m}{ }^{-2} \mathrm{sec}^{-1}$ PAR. Prolonging the drying times at lower RHs of 0 and $23 \%$ required parafilming the Petri dish and making a $\sim 5 \mathrm{~mm}$ incision in the parafilm in order to allow a reduced air flow in the Petri dish; this elevated the RH inside the Petri dish at the onset of drying to close to $98 \%$ in all treatments. 
Stark et al. - Desiccation Tolerance in Syntrichia norvegica page 9

Once the shoots exhibited desiccation morphology (leaves contorted about the stem, visible through the glass desiccator), we waited $4 \mathrm{~d}$ for the shoot WC to equilibrate at the desiccator RH, checking the iButton every $2 \mathrm{~d}$ until at least $12 \mathrm{~h}$ at constant $\mathrm{RH}$ had been reached. At this point, the desiccator was opened and the shoots placed horizontally on premoistened sand media in a Petri dish and placed into the growth chamber under conditions described above under Culture technique. These shoots were watered as needed on a daily basis using sterile distilled water.

\section{Response variables}

Seven d postrehydration visual leaf damage was assessed by examining the shoot at $60 \times$ and assigning each leaf along a shoot to one of 3 categories: entirely chlorophyllose (green, value $=100 \%$ ), partially chlorophyllose (value $=50 \%$ ), or entirely chlorotic (brown, value $=0 \%$ ), with means calculated for each group of 4 shoots treated together. Fourteen d postrehydration the shoot apices were examined and assessed for resumption of apical growth if the shoot apex exhibited phototropism (turning upward). Twenty-one d postrehydration the number of regenerating lateral shoots was counted. For chlorophyll fluorescence, groups of 4 desiccated shoots were rehydrated in a drop of sterile water, cut to $2.5 \mathrm{~mm}$ sections (essentially the shoot crown) and placed in a fluorescence clip on a chemical wipe dipped in water allowing the shoots to remain hydrated and dark adapted for $24 \mathrm{~h}$, after which a modulated chlorophyll fluorometer (FMS2, Hansatech, King's Lynn, UK) incorporating the saturation pulse method (Bilger et al. 1995) to determine the maximum photochemical efficiency of dark-adapted photosystem II $\left(F_{\mathrm{v}} / F_{\mathrm{m}}\right)$ in clips sealed from incident light. Subsequently, the effective quantum yield of PSII photochemistry $\left(\Phi_{P S I I}\right)$ was determined from the following light program on the same shoots: emission of an actinic light ( $300 \mu \mathrm{mol} \mathrm{m} \mathrm{m}^{-2} \mathrm{~s}^{-1}$ PPFD) with 
Stark et al. - Desiccation Tolerance in Syntrichia norvegica page 10

thirty second equilibration periods prior to delivering saturating light pulses (initial 8,000 $\mu \mathrm{mol} \mathrm{m} \mathrm{s}^{-1}$ PPFD) at increasing light intensities (Genty et al. 1989). $F_{\mathrm{v}} / F_{\mathrm{m}}$ is a measure of the general condition of the photocenters, $\Phi_{P S I I}$ represents the fraction of excitation energy flowing through PSII and hence an indicator of active photosynthesis (Green \& Proctor 2016). Additionally, we used the value $F_{\mathrm{m}}$ (maximal fluorescence) to provide a rough comparative measure of the amount of photocenter activity, and thus of the total potential photosynthetic activity and indication of cell damage incurred by the plant material (Proctor 2003). Sample size (number and size of shoots) and distance from the sample $(1 \mathrm{~cm})$ was standardized during measurement. For the chlorophyll fluorescence analyses, three drying treatments were used equating to $30 \mathrm{~min}$ (a rapid-dry), $\sim 100 \mathrm{~h}$ (a slow-dry), and $\sim 200 \mathrm{~h}$ (a very slow-dry) at each of the experimental RHeqs.

\section{Statistics}

Leaf proportion damage was calculated as described under Response variables.

Because of the inherent censoring in these data, Tobit regression models (Tobin 1958) were used to test for the effects of rate of drying $(R o D)$ and equilibrating relative humidity (RHeq) on leaf damage using the R package VGAM (Yee 2015). The effects of $R o D$ and $R H e q$ on regenerative shoot counts were evaluated with negative binomial models using the R package MASS (Venables \& Ripley 2002). One-way ANOVAs were used to partition the effects of RoD and RHeq on the three fluorescence parameters: $F_{\mathrm{v}} / F_{\mathrm{m}}, F_{\mathrm{m}}$, and $\Phi_{P S I I}$. ANOVAs were created for each $R o D$ to compare the fluorescence responses between shoots exposed to different $R H e q$ levels (three per fluorescence parameter). Additional ANOVAs evaluated the effect of RoD within each RHeq level (four per fluorescence parameter). All analyses were performed using R version 3.2.5 (R Core Development Team, 2016). 
Stark et al. - Desiccation Tolerance in Syntrichia norvegica page 11

\section{RESULTS}

\section{Water content (WC), subturgor $\mathrm{RH}$, and equilibrating $\mathrm{RH}$}

On a dry weight basis, WC ranged from $13.45 \%$ at an equilibrating $\mathrm{RH}$ of $75 \%$ to $3.08 \%$ at an equilibrating $\mathrm{RH}$ of $0 \%$ (Table 1). Suprasaturated shoots had a $\mathrm{WC}=$ $3391.50 \pm 331.96 \%(\mathrm{~N}=4)$, and freshly blotted shoots had a $\mathrm{WC}=652.21 \pm 19.19 \%$ ( $\mathrm{N}=16)$. Equilibrating RHs experienced by shoots were $\sim 1-5 \%$ above the target RHs predicted by saturated salt solutions (Table 1), likely influenced by the filter paper upon which the plants rested. Subturgor RH experienced by the shoots during drying was high (excepting the rapidly dried shoots), approaching $98 \%$ for all salt solutions (Table 1). A sample drying curve for a 4-day dry at each of the equilibrating RHs is given in Fig. 2. When the RH inside the Petri dish equilibrates near the target RH of the saturated salt solution, the WC of the plants is also equilibrated (shown in Stark \& Brinda 2015) and not repeated here.

\section{Visual leaf damage}

Leaf damage was significantly affected by both rate of drying $(R o D ; z=2.76$, $\mathrm{df}=2, P=0.017)$ and equilibrating $\mathrm{RH}($ RHeq; $\mathrm{z}=16.25, \mathrm{df}=2, P<0.0001$; Figs. 3, 4). Heavier damage was incurred by shoots dried at lower RHeq relative to higher RHeq in a graded series from $0 \%$ to $75 \%$ RHeq. In addition, longer RoD resulted in less damage than shorter $R o D$, except at $R H e q$ of $54 \%$, where a very slow drying period ( $8 \mathrm{~d})$ resulted in more damage than a $4 \mathrm{~d}$ drying period, more closely approximating damage from a rapid-dry $(\mathrm{RD})$.

\section{Resumption of apical growth}


Stark et al. - Desiccation Tolerance in Syntrichia norvegica page 12

All shoots equilibrated at $75 \% \mathrm{RH}$ exhibited positive shoot apex phototropism regardless of rate of drying (Table 2, Fig. 5a). For shoots equilibrated at 0 and $23 \% \mathrm{RH}$, a tendency for shoot apex positive phototropism occurred at longer rates of drying. However, for a $R H e q=54 \%$, a tendency for reduced shoot apex viability was present at the longer drying rates.

\section{Regenerating lateral shoots}

At drying times up to $\sim 200 \mathrm{~h}$, the number of shoots regenerating from the desiccation treatments was significantly influenced by the $R H e q(\mathrm{z}=7.73, \mathrm{df}=122$, $P<0.0001$ ), with greater regeneration observed at higher $R H e q$ (Figs. 5b, 6). RoD did not have the same influence on shoot regeneration as $R H e q$ within these same drying times $(\mathrm{z}=1.204, \mathrm{df}=122, P=0.229)$. However, when the $R o D$ was extended to $>200 \mathrm{~h}$, the effects of RHeq and $R o D$ on shoot regeneration were not significant as the treatments converged on a regeneration shoot number from $\sim 3-5$ (RHeq: $\mathrm{z}=0.819, \mathrm{df}=50, P=0.413$; $R o D: \mathrm{z}=-1.419, \mathrm{df}=50, P=0.156$ ). All but 14 shoots (of a total of 172 tested) regenerated by forming new lateral shoots, with 12 of these non-regenerating shoots equilibrated at $0 \%$ RH.

\section{Chlorophyll fluorescence}

Overall the fluorescence parameters were significantly influenced individually by $R o D\left(F_{\mathrm{m}} F=26.09, \mathrm{df}=3, P<0.0001 ; F_{\mathrm{v}} / F_{\mathrm{m}} F=47.73, \mathrm{df}=3, P<0.0001 ; \Phi_{P S I I} F=51.28\right.$, $\mathrm{df}=3, P<0.0001)$ and RHeq $\left(F_{\mathrm{m}} F=7.40, \mathrm{df}=2, P=0.001 ; F_{\mathrm{v}} / F_{\mathrm{m}} F=12.86, \mathrm{df}=3, P<0.0001\right.$; $\Phi_{P S I I} F=10.45, \mathrm{df}=2, P=0.0001 ;$ Figs $\left.7, \mathbf{8}, 9\right)$. For $F_{\mathrm{m}}$, the combined influence of these two factors was marginally significant $\left(R o D \times R H e q: F_{\mathrm{m}} F=1.98, \mathrm{df}=6, P=0.08\right)$. However, for $F_{\mathrm{v}} / F_{\mathrm{m}}$ and $\Phi_{P S I I}$ the combined influence of RoD and RHeq was significant $\left(R o D \times R H e q: F_{\mathrm{v}} / F_{\mathrm{m}} F=3.55, \mathrm{df}=6, P=0.005 ; \Phi_{P S I I} F=1.04, \mathrm{df}=6, P=0.002\right)$. Control 
Stark et al. - Desiccation Tolerance in Syntrichia norvegica page 13

levels of $F_{\mathrm{v}} / F_{\mathrm{m}}$ (quantum yield) for unstressed shoot tips were $\sim 0.60$, and these levels were only approached for the very slow rate of drying $(R o D)$ period $(8 \mathrm{~d})$ at an equilibrating $\mathrm{RH}(\mathrm{RHeq})=75 \%$ (Fig. 7). Additionally, other than control values, maximal $\Phi_{P S I I}$ (quantum efficiency of Photosystem II) and $F_{\mathrm{m}}$ (maximal fluorescence) values were only attained by shoots dried at $75 \% \mathrm{RH}$ at the most rapid $R o D$ (30 min: $\left.\Phi_{P S I I} F=40.006, \mathrm{df}=3, P<0.0001 ; F_{\mathrm{m}} F=7.986, \mathrm{df}=3, P=0.0001\right)$ and at the slowest $R o D(8$ d: $\left.\Phi_{P S I I} F=8.200, \mathrm{df}=3, P=0.0009 ; F_{\mathrm{m}} F=10.68, \mathrm{df}=3, P=0.0002\right)$. Shoots dried at $54 \%$ RH had fluorescence values similar to those dried at lower $R H e q$ when dried rapidly (30 min) or slowly ( $8 \mathrm{~d})$. However, the $R o D$ mitigated $F_{\mathrm{v}} / F_{\mathrm{m}}$ and $\Phi_{P S I I}$ values at $R H e q$ of $54 \% \mathrm{RH}$ making them indistinguishable from the $75 \% \mathrm{RH}$ values under the same $\mathrm{RoD}$ regime of $4 \mathrm{~d}\left(F_{\mathrm{v}} / F_{\mathrm{m}} F=1.835, \mathrm{df}=1, P=0.2027 ; \Phi_{P S I I} F=0.8927, \mathrm{df}=1, P=0.365\right)$.

\section{DISCUSSION}

\section{Constitutive hypothesis not supported}

We hypothesized that $S$. norvegica would exhibit an ecologically constitutive response pattern to desiccation stress, meaning that upon exposure to various rates of drying and water contents that shoots would exhibit minimal damage upon rehydration. This hypothesis is consistent with (1) literature reports from at least three species in the genus (S. caninervis, S. pagorum, S. ruralis; Zhang et al. 2011, Oliver et al. 2005, Stark et al. 2012, 2016a) and (2) reports of 6 species of Syntrichia (including S. norvegica) tolerating equilibration with $\leq 30 \%$ RH (Wood 2007). However, most previous studies implemented a desiccation treatment based on "intensity", which combines the factors of rate of drying $(R o D)$ and equilibrating relative humidity $($ RHeq). When these factors are separated, a response pattern that cannot be easily characterized as either constitutively or 
Stark et al. - Desiccation Tolerance in Syntrichia norvegica page 14

inducibly desiccation tolerant (DT) emerges for S. norvegica. Both RoD and RHeq significantly affected chlorophyll fluorescence parameters on an individual basis, and, importantly, RoD and RHeq interacted significantly for $F_{\mathrm{v}} / F_{\mathrm{m}}$ and $\Phi_{P S I I}$. These two parameters relate to the efficiency of photosynthesis, indicating that the biochemistry of PSII is affected by the combined stresses of $R o D$ and $R H e q$ historically regarded as desiccation intensity. When shoot apices are rapidly dried $(<30 \mathrm{~min}$ from full turgor to desiccation morphology), damage is severe at all equilibrating RHs (RHeq) except 75\%. However, as $R o D$ is extended to $4 \mathrm{~d}$, a clear inducible response across WCs is present. Extending the $R o D$ to $\sim 8 \mathrm{~d}$ further improved plant health upon rehydration except at an intermediate WC (RHeq 54\%). Based upon $F_{\mathrm{m}}$ values, regardless of the RoD or the RHeq, some rehydration damage is present (that was not detected visually), although based upon $F_{\mathrm{v}} / F_{\mathrm{m}}$ and $\Phi_{P S I I}$ values, a drying regime resulting in negligible damage occurs at a $R o D$ of $8 \mathrm{~d}$ at a $R H e q$ of $75 \%$. When the ability to regenerate through shoot production $21 \mathrm{~d}$ postrehydration is considered, equilibrating $\mathrm{RH}$ is senior to $\mathrm{RoD}$, and no combination of $R o D \times R H e q$ approaches the regeneration level of control shoots. We conclude that in the high elevation species $S$. norvegica, the response to desiccation is generally that of inducible desiccation tolerance (IDT), but the response pattern depends upon the interaction between $R o D$ and RHeq. At RHeqs below 50\%, shoots are significantly damaged based on chlorophyll fluorescence, visual leaf damage, and regeneration potential, although even in these cases actual shoot death was rare (3 instances). At these depressed WCs, a slight inducible effect is observed at long drying times, but heavy damage is the general pattern observed. At a $R H e q \sim 54 \%$, when the $R o D$ is extended from $4 \mathrm{~d}$ to $8 \mathrm{~d}$, shoots are severely damaged, a puzzling result confirmed by 
Stark et al. - Desiccation Tolerance in Syntrichia norvegica page 15

visual assessment of leaf damage, shoot apex viability, and independent fluorescence assessments, but not reflected in shoot regeneration numbers $21 \mathrm{~d}$ postrehydration.

The variation we observed when shoots were dried over a period of $8 d$ at $\sim 54 \%$ $\mathrm{RH}$ may arise from the influence of WC on membrane stability. At water contents approaching $0.1 \mathrm{~g} \mathrm{~g}^{-1} \mathrm{DWt}(=10 \%)$ associated with a $R H e q \sim 50 \%$, membranes transition from a liquid crystalline to gel phase (Crowe \& Crowe 1982). Damage to the lipid bilayer during this phase change can allow imbibitional leakage during rehydration (Hoekstra et al. 1999). Previous research indicates that the related S. ruralis and $S$. caninervis do not experience membrane damage during desiccation, suggesting a constitutive strategy of DT (Singh 1984; Wu et al. 2012). The current study suggests that S. norvegica may rely more on inducible protection conferred during slow drying episodes; we caution that previous studies did not always fully deharden plants, opening the door to a hardened effect that mimics CDT (Stark et al. 2014). Additionally, critical enzymatic activity relevant to tolerating desiccation in mosses depends upon the phase state of the membrane (Fernández-Marin et al. 2013). It is possible that some shoots in our experiment experienced a membrane phase change or a partial phase change, and this may have produced some of the wide variation we observed with this particular treatment.

\section{Water content}

Water content (WC), as varied through equilibrating RH (RHeq), appears to be of senior importance to postrehydration health of S. norvegica shoot apices. When shoots are dried to $\mathrm{RHeq}<\sim 75 \%$ (equating to $\mathrm{WCs}<13 \%$ ) and dried rapidly, upon rehydration all shoots are heavily damaged. Even slowly drying shoots to WCs $<7 \% \mathrm{DWt}$ (RHeq $<25 \%$ ) resulted in severe shoot damage upon rehydration. Vulnerability at low WCs is 
Stark et al. - Desiccation Tolerance in Syntrichia norvegica page 16

likely due to (1) a sudden membrane phase change upon rehydration as noted earlier and (2) failure to reorganize the photosynthetic apparatus upon rehydration, which is less likely to occur at RHeqs $>50 \%$ (Fernández-Marin et al. 2013). This effect was not observed in the related $S$. ruralis, where "slow drying" (only $\sim 1 \mathrm{~h}$ ) to equilibrating RHs below $22 \%$ produced minimal damage to shoot apices upon rehydration (Schonbeck \& Bewley 1981). Clearly the level of inherent DT in S. ruralis is greater than that observed in the higher elevation $S$. norvegica, with data from the latter species consistent with mosses normally occurring in shaded habitats (Oliver et al. 1993; Proctor et al. 2007).

\section{Suprasaturation effects}

By varying drying rates (as time from full turgor to leaf curling) from $30 \mathrm{~min}$ to 8 days across a range of equilibrating RHs, we attempted to approximate the minimum rate of drying at specific water contents that resulted in minimal shoot damage upon rehydration. Only one set of drying conditions was found where the shoot health approached that of undried controls: an $8 \mathrm{~d}$ drying time at a $\mathrm{RHeq}$ of $\sim 75 \%$, equating to a WC of $13.4 \%$ on a DWt basis. Reasons for this rather restrictive finding may lie in the techniques used to assess DT in this species. First, cultures of $S$. norvegica were intentionally maintained in a suprasaturated condition, where external water persists along the shoots and especially in the concave pockets of adaxial leaf surfaces. Suprasaturated conditions do not appear to appreciably decrease net photosynthesis in Syntrichia (Seel et al. 1992) and in several other species of bryophytes ( $20 \%$ reduction; Dilks \& Proctor 1979) for reasons detailed in Proctor (2008) and Green et al. (2011). Cultures of S. norvegica, with a WC at suprasaturation of $\sim 3400 \%$, were vigorous and healthy as assessed visually and through chlorophyll fluorescence. Nevertheless, cushion WCs of $\sim 700 \%$ decreased net photosynthesis in Grimmia pulvinata by nearly half (Zotz 
Stark et al. - Desiccation Tolerance in Syntrichia norvegica page 17

et al. 2000) and decreased NP in S. ruralis by $38 \%$ (Zotz \& Rottenberger 2001). Control $F_{\mathrm{v}} / F_{\mathrm{m}}$ values are on the low side $(\sim 0.6)$, but well within what is considered normal for unstressed bryophytes, including Syntrichia (e.g., Csintalan et al. 1999; Hamerlynck et al. 2000; Beckett et al. 2005). The high suprasaturation WC of S. norvegica shoots even exceeds that reported for species of Sphagnum (Schipperges \& Rydin 1998; Hájek \& Beckett 2008). Growing plants in the suprasaturated condition prevented any hardening to DT during the growth of the cultures through partial dehydration, which may occur during the normal course of growth when shoot apices lose turgor, even at RHeqs near 98\% (Hájek \& Vicherová 2014), and thus allowed an assessment of the inherent DT in the shoot apices. Second, shoots were rehydrated directly from the desiccators into relatively cool $\left(\sim 2-4^{\circ} \mathrm{C}\right)$ liquid water, without an opportunity to prehydrate. Although prehydration (exposure to high RH prior to liquid water) is rarely part of the protocol in plant DT studies, there is some evidence that exposing desiccated bryophyte shoots to high RHs for several hours prior to immersing in liquid water mitigates some desiccation induced damage in S. ruralis (e.g., Schonbeck \& Bewley 1981 and reviewed in Stark et al. 2016b), and prehydration is likely to occur in natural colonies of mosses.

\section{Stem tissue and shoot apices are highly DT}

In the related $S$. ruraliformis and $S$. ruralis, the shoot apex is often the most resistant to desiccation stress (Dilks \& Proctor 1974; Schonbeck \& Bewley 1981). Our findings for S. norvegica reflect this pattern, with most visual leaf damage occurring on proximal leaves. This phenomenon is well known among mosses (e.g., Glime \& Carr 1974; Gupta 1977; Beckett 2001; Proctor \& Pence 2002; Stark et al. 2013 and references therein) and is likely a widespread phenomenon. Despite the severe shoot damage associated with lower water contents in $S$. norvegica, in all cases but 14 , upon 
Stark et al. - Desiccation Tolerance in Syntrichia norvegica page 18

rehydration shoots regenerated through lateral shoots, and of these 11 regenerated solely through protonemata. In other words, even though experiencing a range of drying times across a range of WCs, 169 of 172 shoots were capable of regeneration (the 3 shoots that died were rapidly dried). This speaks to a constitutive DT mechanism of at least some stem tissues. We hypothesize that axillary leaf buds are phenotypically CDT and that such an adaptation may greatly assist in withstanding severe desiccation events through asexual regeneration.

\section{Conclusion}

In this study we showed that the high elevation species $S$. norvegica departs from the pattern (or assumption) of a strategy of inherent phenotypic constitutive DT in the genus. By separating the factor of "desiccation intensity" into its component parts of rate of drying and equilibrating relative humidity (or water content here), the pattern of DT for this species is found to vary within a specific water content based on how fast the shoots were desiccated. As the drying time is extended, an incomplete pattern of inducible DT was observed across all water contents tested. At the highest WC tested, recovery of shoots approached control undried shoots. However, at lower WCs, even the longest rates of drying did not translate into full recovery of shoots. Separation of environmental factors experienced by plants during desiccation may open potential avenues to investigate a proliferation of strategies adopted by mosses to tolerate desiccation. Species may exhibit a diversity of responses through an integration and coordination of physiological, morphological, and reproductive DT strategies. Future studies should factor in the process of prehydration of shoots prior to rehydration with liquid water, and compare the DT in suprasaturated shoots vs. shoots maintained at full turgor without significant external water. 
Stark et al. - Desiccation Tolerance in Syntrichia norvegica page 19

\section{ACKNOWLEDGEMENTS}

The authors thank the University of Nevada, Las Vegas (UNLV) for granting a research sabbatical to LRS during the course of this study, the School of Life Sciences (UNLV) for funding laboratory supplies and equipment repair, UNLV graduate assistance support for JLG, a National Science Foundation Graduate Research Fellowship to MLS, and R. Riker for assistance in composing the photographic plates. The comments of an anonymous reviewer strengthened the manuscript.

\section{REFERENCES}

Alpert, P. 2005. The limits and frontiers of desiccation-tolerant life. Integr. Comp. Biol. 45: 685-695. doi: 10.1093/icb/45.5.685.

Alpert, P. 2006. Constraints of tolerance: why are desiccation-tolerant organisms so small or rare? J. Exp. Biol. 209: 1575-1584. doi: 10.1242/jeb.02179. PMID: 16621938. Beckett, R.P. 2001. ABA-induced tolerance to ion leakage during rehydration following desiccation in the moss Atrichum androgynum. Plant Growth Regul. 35: 131-135. doi: 10.1023/A:1014477603983.

Beckett, R.P., Marschall, M., and Laufer, Z. 2005. Hardening enhances photoprotection in the moss Atrichum androgynum during rehydration by increasing fast- rather than slow-relaxing quenching. J. Bryol. 27: 7-12. doi:

$10.1179 / 174328205 X 40536$.

Bewley, J.D. 1995. Physiological aspects of desiccation tolerance - a retrospect. Int. J. Plant Sci. 156: 393-403. 
Stark et al. - Desiccation Tolerance in Syntrichia norvegica page 20

Bilger, W., Schreiber, U., and Bock, M. 1995. Determination of the quantum efficiency of photosystem II and of non-photochemical quenching of chlorophyll fluorescence in the field. Oecologia 102: 425-432. doi: 10.1007/BF00341354.

Brinda, J.C., Stark, L.R., Clark, T.A., and Greenwood, J.L. 2016. Embryos of a moss can be hardened to desiccation tolerance: effects of rate of drying on the timeline of recovery and dehardening in Aloina ambigua (Pottiaceae). Ann. Bot. 117: 153163. doi: 10.1093/aob/mcv136. PMID: 26354931.

Buda, G.J., Barnes, W.J., Fich, E.A., Park, S., Yeats, T.H., Zhao, L., Domozych, D.S., and Rose, J.K.C. 2013. An ATP binding cassette transporter is required for cuticular wax deposition and desiccation tolerance in the moss Physcomitrella patens. Plant Cell 25: 4000-4013. doi: 10.1105/tpc.113.117648. PMID: 24163310.

Crowe, J.H. and Crowe, L.M. 1982. Induction of anhydrobiosis: membrane changes during drying. Cryobiology 19: 317-328. doi: 10.1016/0011-2240(82)90160-2.

Csintalan, Z., Proctor, M.C.F., and Tuba, Z. 1999. Chlorophyll fluorescence during drying and rehydration in the mosses Rhytidiadelphus loreus (Hedw.) Warnst., Anomodon viticulosus (Hedw.) Hook. \& Tayl. and Grimmia pulvinata (Hedw.) Sm. Ann. Bot. 84: 235-244. doi: 10.1006/anbo.1999.0919.

Dilks, T.J.K., and Proctor, M.C.F. 1974. The pattern of recovery of bryophytes after desiccation. J. Bryol. 8: 97-115. doi: 10.1179/jbr.1974.8.1.97.

Dilks, T.J.K., and Proctor, M.C.F. 1979. Photosynthesis, respiration and water content in bryophytes. New Phytol. 82: 97-114. doi: 10.1111/j.1469-8137.1979.tb07564.

Fernández-Marín, B., Kranner, I., San Sebastián, M., Artetxe, U., Laza, J.M., Vilas, J.L., Pritchard, H.W., Nadajaran, J., Miguez, F., Becerril, J.M., and Garcia-Plazaola, 
Stark et al. - Desiccation Tolerance in Syntrichia norvegica page 21

J.I. 2013. Evidence for the absence of enzymatic reactions in the glassy state. A case study of xanthophyll cycle pigments in the desiccation-tolerant moss Syntrichia ruralis. J. Expt. Bot. 64: 3033-3043. doi: 10.1093/jxb/ert.145. PMID: 23761488.

Gabriel, W. 2005. How stress selects for reversible phenotypic plasticity. J. Evol. Biol. 18: 873-883. doi: 10.1111/j.1420-9101.2005.00959.x. PMID: 16033559.

Genty, B., Briantais, J., and Baker, N.R. 1989. The relationship between the quantum yield of photosynthetic electron transport and quenching of chlorophyll fluorescence. Biochim. Biophys. Acta 990: 87-92. doi: 10.1016/S03044165(89)80016-9.

Glime, J.M., and Carr, R.E. 1974. Temperature survival of Fontinalis novae-angliae Sull. Bryologist 77: 17-22. doi: 10.2307/3241772.

Green, T.G.A., and Proctor, M.C.F. 2016. Physiology of photosynthetic organisms within biological soil crusts: their adaptation, flexibility, and plasticity. In Biological soil crusts: an organizing principle in drylands. Edited by B. Weber, B. Büdel, J. Belnap. Ecological Studies 226, Springer, AG Switzerland. pp. 347-381.

Green, T.G.A., Sancho, L.G., and Pintado, A. 2011. Ecophysiology of desiccation/rehydration cycles in mosses and lichens. In Plant Desiccation Tolerance. Edited by U. Lüttge, E. Beck, \& D. Bartels. Ecological Studies 215, Springer-Verlag, Berlin. pp. 89-120.

Gupta, R.K. 1977. A study of photosynthesis and leakage of solutes in relation to the desiccation effects in bryophytes. Can. J. Bot. 55: 1186-1194. doi: 10.1139/b77138. 
Stark et al. - Desiccation Tolerance in Syntrichia norvegica page 22

Hájek, T., and Beckett, R.P. 2008. Effect of water content components on desiccation and recovery in Sphagnum mosses. Ann. Bot. 101: 165-173. doi: 10.1093/aob/mcm287. PMID: 18024417.

Hájek, T., and Vicherová, E. 2014. Desiccation tolerance of Sphagnum revisited: a puzzle resolved. Plant Biology 16: 765-773. doi: 10.1111/plb.12126. PMID: 25068160.

Hamerlynck, E.P., Tuba, Z., Csintalan, Z., Nagy, Z., Henebry, G., and Goodin, D. 2000. Diurnal variation in photochemical dynamics and surface reflectance of the desiccation-tolerant moss, Tortula ruralis. Plant Ecol. 151: 55-63. doi: 10.1023/A:1026594623578.

Hoagland, D.R., and Arnon, D.I. 1938. The water-culture method for growing plants without soil. California Agricultural Experiment Station Circular 347: 1-39.

Hoekstra, F.A., Golovina, E.A., van Aelst, A.C., and Hemminga, M.A. 1999. Imbibitional leakage from anhydrobiotes revisited. Plant Cell Environ. 22: 11211131. doi: 10.1046/j.1365-3040.1999.00491.x.

Oliver, M.J., Mishler, B.D., and Quisenberry, J.E. 1993. Comparative measures of desiccation-tolerance in the Tortula ruralis complex. I. Variation in damage control and repair. Am. J. Bot. 80: 127-136. doi: 10.2307/2445030.

Oliver, M.J., Velten, J., and Mishler, B.D. 2005. Desiccation tolerance in bryophytes: a reflection of the primitive strategy for plant survival in dehydrating habitats? Integr. Comp. Biol. 45: 788-799. doi: 10.1093/icb/45.5.788.

Pressel, S., and Duckett, J.G. 2010. Cytological insights into the desiccation biology of a model system: moss protonemata. New Phytol. 185: 944-963. doi: 10.1111/j.1469-8137.2009.03148.x. PMID: 20100204. 
Stark et al. - Desiccation Tolerance in Syntrichia norvegica page 23

Proctor, M.C.F. 2001. Patterns of desiccation tolerance and recovery in bryophytes. Plant Growth Regul. 35: 147-156. doi: 10.1023/A:1014429720821.

Proctor, M.C.F. 2003. Experiments on the effect of different intensities of desiccation on bryophyte survival, using chlorophyll fluorescence as an index of recovery. J. Bryol. 25: 201-210. doi: 10.1179/037366803235001652.

Proctor, M.C.F. 2008. Physiological ecology. In Bryophyte biology. Edited by B. Goffinet, A.J. Shaw. Cambridge University Press, Cambridge. pp. 237-268.

Proctor, M.C.F., and Pence, V.C. 2002. Vegetative tissues: bryophytes, vascular 'resurrection plants' and vegetative propagules. In Desiccation and plant survival. Edited by Pritchard, H., Black, M. CABI Publishing, Wallingford, UK. pp. 207237.

Proctor, M.C.F., Oliver, M.J., Wood, A.J., Alpert, P., Stark, L.R., Cleavitt, N.L., and Mishler, B.D. 2007. Desiccation-tolerance in bryophytes: a review. Bryologist 110: $595-621$.

R Core Team (2016). R: A language and environment for statistical computing. $\mathrm{R}$ Foundation for Statistical Computing, Vienna, Austria. URL https://www.Rproject.org/.

Rice, S.K. 2012. The cost of capillary integration for bryophyte canopy water and carbon dynamics. Lindbergia 35: 53-62.

Rundel, P.W., and Lange, O.L. 1980. Water relations and photosynthetic response of a desert moss. Flora 169: 329-335.

Schipperges, B., and Rydin, H. 1998. Response of photosynthesis of Sphagnum species from contrasting microhabitats to tissue water content and repeated desiccation. New Phytol. 140: 677-684. doi: 10.1046/j.1469-8137.1998.00311.x. 
Stark et al. - Desiccation Tolerance in Syntrichia norvegica page 24

Schonbeck, M.W., and Bewley, J.D. 1981. Responses of the moss Tortula ruralis to desiccation treatments. I. Effects of minimum water content and rates of dehydration and rehydration. Can. J. Bot. 59: 2698-2706. doi: 10.1139/b81-320.

Seel, W.E., Baker, N.R., and Lee, J.A. 1992. Analysis of the decrease in photosynthesis on desiccation of mosses from xeric and hydric environments. Physiol. Plant. 86: 451-458. doi: 10.1111/j.1399-3054.1992.tb01343.x.

Singh, J., Blackwell, B.A, Miller, R.W., and Bewley, J.D. 1984. Membrane organization of the desiccation-tolerant moss Tortula ruralis in dehydrated states. Plant Physiol. 75: 1075-1079.

Stark, L.R., and Brinda, J.C. 2015. Developing sporophytes transition from an inducible to a constitutive ecological strategy of desiccation tolerance in the moss Aloina ambigua: effects of desiccation on fitness. Ann. Bot. 115: 593-603. doi: 10.1093/aob/mcu252. PMID: 25578378.

Stark, L.R., Brinda, J.C., and Greenwood, J.L. 2016a. Propagula and shoots of Syntrichia pagorum (Pottiaceae) exhibit different ecological strategies of desiccation tolerance. Bryologist 119: 181-192. doi: 10.1639/0007-2745-119.2.181.

Stark, L.R., Brinda, J.C., McLetchie, D.N., and Oliver, M.J. 2012. Extended periods of hydration do not elicit dehardening to desiccation tolerance in regeneration trials of the moss Syntrichia caninervis. Int. J. Plant Sci. 173: 333-343. doi: $10.1086 / 663970$.

Stark, L.R., Greenwood, J.L., Brinda, J.C., and Oliver, M.J. 2013. The desert moss Pterygoneurum lamellatum exhibits inducible desiccation tolerance: effects of rate of drying on shoot damage and regeneration. Am. J. Bot. 100: 1522-1531. doi: 10.3732/ajb.1200648. PMID: 23876454. 
Stark et al. - Desiccation Tolerance in Syntrichia norvegica page 25

Stark, L.R., Greenwood, J.L., Brinda, J.C., and Oliver, M.J. 2014. Physiological history may mask the inherent inducible desiccation tolerance strategy of the desert moss Crossidium crassinerve. Plant Biology 16: 935-946. doi: 10.1111/plb.12140. PMID: 24397604.

Stark, L.R., McLetchie, D.N., Greenwood, J.L., and Eppley, S.M. 2016b. Moss antheridia are desiccation tolerant: rehydration dynamics influence sperm release in Bryum argenteum. Am. J. Bot. 103: 856-864. doi: 10.3732/ajb.1600026. PMID: 27208354.

Tobin, J. 1958. Estimation of relationships for limited dependent variables. Econometrica 26: $24-36$.

Venables, W.N., and Ripley, B.D. 2002. Modern Applied Statistics with S, Fourth edition. Springer, New York, USA.

Walters, C., Hill, L.M., and Wheeler, L.J. 2005. Dying while dry: kinetics and mechanisms of deterioration in desiccated organisms. Integr. Comp. Biol. 45: 751-758. doi: 10.1093/icb/45.5.751.

Werner, O., Ros Espín, R.M., Bopp, M., and Atzorn, R. 1991. Abscisic-acid-induced drought tolerance in Funaria hygrometrica Hedw. Planta 186: 99-103. doi: 10.1007/BF00201503. PMID: 24186580.

Wolfe, J. and Bryant, C. 1999. Freezing, drying, and/or vitrification of membrane-solutewater systems. Cryobiology 39: 103-129. doi: 10.1006/cryo.1999.2195. PMID: 10529304.

Wood, A.J. 2007. The nature and distribution of vegetative desiccation tolerance in hornworts, liverworts and mosses. Bryologist 110: 163-177. doi: 10.1639/00072745(2007)110[163:IENFIB]2.0.CO;2. 
Stark et al. - Desiccation Tolerance in Syntrichia norvegica page 26

Wood, A.J., and Oliver, M.J. 1999. Translational control in plant stress: the formation of messenger ribonucleoprotein particles (mRNPs) in response to desiccation of Tortula ruralis gametophytes. Plant J. 18: 359-370. doi: 10.1046/j.1365313X.1999.00458.x.

Wu, N., Zhang, Y.M., Downing, A., Zhang, J., and Yang, C.H. 2012. Membrane stability of the desert moss Syntrichia caninervis Mitt. during desiccation and rehydration. J. Bryol. 34: 1-8. doi: 10.1179/1743282011Y.0000000043.

Yee, T.W. 2015. VGAM: Vector generalized linear and additive models: with an implementation in R. Springer, New York, USA.

Zhang, J., Zhang, Y.-M, Downing, A., Wu, N., and Zhang, B.-C. 2011. Photosynthetic and cytological recovery on remoistening Syntrichia caninervis Mitt., a desiccation-tolerant moss from Northwestern China. Photosynthetica 49: 13-20. doi: 10.1007/s11099-011-0002-6.

Zotz, G., and Rottenberger, S. 2001. Seasonal changes in diel $\mathrm{CO}_{2}$ exchange of three central european moss species: a one-year field study. Plant Biology 3: 661-669. doi: $10.1055 / \mathrm{s}-2001-19363$.

Zotz, G., Schweikert, A., Jetz, W., and Westerman, H. 2000. Water relations and carbon gain are closely related to cushion size in the moss Grimmia pulvinata. New Phytol. 148: 59-67. doi: 10.1046/j.1469-8137.2000.00745.x. 
Stark et al. - Desiccation Tolerance in Syntrichia norvegica page 27

Table 1. Salt solutions and their target relative humidities, equilibrating relative humidities (RHeq) experienced by plants, subturgor RH experienced by plants during a representative drying trial, temperatures $(\mathrm{T})$ experienced by plants during an equilibration, and water contents (WC) attained in the desiccators containing shoots of Syntrichia norvegica; RHeq and T represent means of the last $12 \mathrm{~h}$ in the desiccator, subturgor $\mathrm{RH}$ represents means of the first $24 \mathrm{~h}$ in the desiccator during a $\sim 8 \mathrm{~d}$ drying event, and WC is based on dry weight $(\mathrm{DWt},=100 \times[($ Experimental Wt - Dry Wt $) /$ Dry Wt]. Means with one SE, N=44-47 for RHeq \& T, N=24 for Subturgor RH, N=4 for WC.

\begin{tabular}{|lcccc|}
\hline $\begin{array}{c}\text { Salt Solution } \\
\text { (target } \mathbf{R H} \text { at } \\
\left.\mathbf{2 0}^{\circ} \mathbf{C}\right)\end{array}$ & RHeq & $\begin{array}{c}\text { Subturgor } \\
\mathbf{R H}\end{array}$ & $\begin{array}{c}\text { T during } \\
\text { Equilibration }\end{array}$ & $\begin{array}{c}\text { WC at } \\
\text { Equilibration } \\
\text { (\% DW) }\end{array}$ \\
\hline \hline $\mathbf{N a C l ~ ( 7 5 \% )}$ & $79.01 \pm 0.12$ & $99.61 \pm 0.13$ & $20.19 \pm 0.02$ & $13.45 \pm 1.16$ \\
$\mathbf{M g}\left(\mathbf{N O}_{\mathbf{3}}\right)_{\mathbf{2}}(\mathbf{5 4 \% )}$ & $59.36 \pm 0.16$ & $98.46 \pm 0.23$ & $20.16 \pm 0.00$ & $11.40 \pm 0.20$ \\
$\mathbf{K C H}_{\mathbf{3}} \mathbf{C O}_{\mathbf{2}}(\mathbf{2 3 \%})$ & $25.95 \pm 0.16$ & $98.69 \pm 0.20$ & $20.17 \pm 0.04$ & $6.98 \pm 0.48$ \\
$\mathbf{C a S O}_{\mathbf{4}}(\mathbf{s})(\mathbf{0 \%})$ & $00.64 \pm 0.22$ & $97.90 \pm 0.14$ & $20.55 \pm 0.03$ & $3.08 \pm 0.72$ \\
\hline
\end{tabular}


Stark et al. - Desiccation Tolerance in Syntrichia norvegica page 28

Table 2. Percentage of Syntrichia norvegica shoot apices exhibiting positive phototropism (indicating viability of apical meristem) 14 days postrehydration based on equilibrating $\mathrm{RH}(\mathrm{RHeq})$ and rate of drying $(\mathrm{RoD})$; shoot number $(\mathrm{N})$ given parenthetically.

\begin{tabular}{|cccc|}
\hline \multicolumn{5}{|c|}{$\boldsymbol{R o D}(\mathbf{h})$} \\
\hline \hline $\boldsymbol{R H e q}(\boldsymbol{\%})$ & $\underline{\mathbf{5 0}}$ & $\underline{\mathbf{5 0}-\mathbf{1 4 9}}$ & $\underline{\mathbf{1 5 0 +}}$ \\
$\mathbf{0}$ & $0(20)$ & $40(20)$ & $33(12)$ \\
$\mathbf{2 3}$ & $0(8)$ & $94(16)$ & $50(8)$ \\
$\mathbf{5 4}$ & $94(16)$ & $100(12)$ & $69(16)$ \\
\hline
\end{tabular}


Stark et al. - Desiccation Tolerance in Syntrichia norvegica page 29

Fig. 1. Appearance of cultured shoots of Syntrichia norvegica exhibiting (A) the suprasaturated condition, whereby free water is stored in the shoot apices and concave spaces of the adaxial leaf surfaces, and (B) (the same) shoots without appreciable external water.

Fig. 2. Relative humidity (RH) experienced by shoots of Syntrichia norvegica during an experimental 4-day rate of drying at four targeted equilibrating RHs. Dotted line at $\sim 86 \%$ $\mathrm{RH}$, where leaf curling begins. When the RH equilibrates at the targeted level, shoot water content also equilibrates. Photo insets indicate a shoot at full turgor (no external water) at the initiation of the experimental dry-down, and the same shoot that has equilibrated in a desiccated condition.

Fig. 3. Range of shoot damage experienced by shoot apices of Syntrichia norvegica on day 7 postrehydration from a desiccation treatment. (A) undried control, (B) dried $126 \mathrm{~h}$ and equilibrated at 75\% RH (minor damage), (C) dried $127 \mathrm{~h}$ and equilibrated at 54\% $\mathrm{RH}$ (moderate damage), and (D) rapidly dried ( $<30 \mathrm{~min}$ ) and equilibrated at 23\% $\mathrm{RH}$ (severe damage).

Fig. 4. Visual leaf damage (as the percentage of leaves along a shoot that are chlorophyllous) day 7 postrehydration on shoots of Syntrichia norvegica subjected to a range of drying times at targeted equilibrating relative humidities of $0,23,54$, and $75 \%$. Each point represents a mean and one S.E. $(\mathrm{N}=4)$ with fitted unweighted polynomial curves. 
Stark et al. - Desiccation Tolerance in Syntrichia norvegica page 30

Fig. 5. Examples of positive or no shoot apex phototropism and lateral shoot regeneration as seen on day 21 postrehydration from a desiccation treatment in Syntrichia norvegica. (A) four shoots rapidly dried ( $<30 \mathrm{~min}$ ) and equilibrated at $75 \% \mathrm{RH}$, all shoot apices exhibiting positive phototropism and abundant lateral shoot production, (B) dried $38 \mathrm{~h}$ and equilibrated at $23 \% \mathrm{RH}, 0$ shoot apices viable yet some lateral shoot regeneration (at arrows).

Fig. 6. Lateral shoot regeneration day 21 postrehydration on shoots of Syntrichia norvegica subjected to a range of drying times at targeted equilibrating relative humidities of $0,23,54$, and $75 \%$. Each point represents a mean and one S.E. $(\mathrm{N}=4)$ with fitted unweighted polynomial curves.

Fig. 7. Maximum photochemical efficiency of dark-adapted photosystem II as $F_{\mathrm{v}} / F_{\mathrm{m}}$ at 24-h postrehydration on shoot apices of Syntrichia norvegica subjected to a range of drying times at targeted equilibrating relative humidities of $0,23,54$, and $75 \%$. Each point represents a mean and one S.E. $(\mathrm{N}=6)$ with fitted unweighted polynomial curves. Mean drying time \pm one S.E. for each relative humidity treatment: $0 \% 4 \mathrm{~d}=114 \pm 9 \mathrm{~h}, 0 \%$ $8 d=204 \pm 18 h, 23 \% 4 d=106 \pm 7$ h, 23\% 8d=212 \pm 6 h, $54 \% 4 d=99 \pm 8$ h, $54 \% 8 d=$ $183 \pm 2 \mathrm{~h}, 75 \% 4 \mathrm{~d}=92 \pm 6 \mathrm{~h}, 75 \% 8 \mathrm{~d}=194 \pm 10 \mathrm{~h}$.

Fig. 8. Maximal chlorophyll fluorescence as $F_{\mathrm{m}}$ at 24-h postrehydration on shoot apices of Syntrichia norvegica subjected to a range of drying times at targeted equilibrating relative humidities of $0,23,54$, and $75 \%$. Each point represents a mean and one S.E. 
Stark et al. - Desiccation Tolerance in Syntrichia norvegica page 31

$(\mathrm{N}=6)$ with fitted unweighted polynomial curves. For mean drying time \pm one S.E. for each treatment $\mathrm{N}$ see caption Fig. 7.

Fig. 9. Effective quantum yield of PSII photochemistry as $\Phi_{P S I I}$ at 24-h postrehydration on shoot apices of Syntrichia norvegica subjected to a range of drying times at targeted equilibrating relative humidities of $0,23,54$, and $75 \%$. Each point represents a mean and one S.E. $(\mathrm{N}=6)$ with fitted unweighted polynomial curves. For mean drying time \pm one S.E. for each treatment $\mathrm{N}$ see caption Fig. 7. 

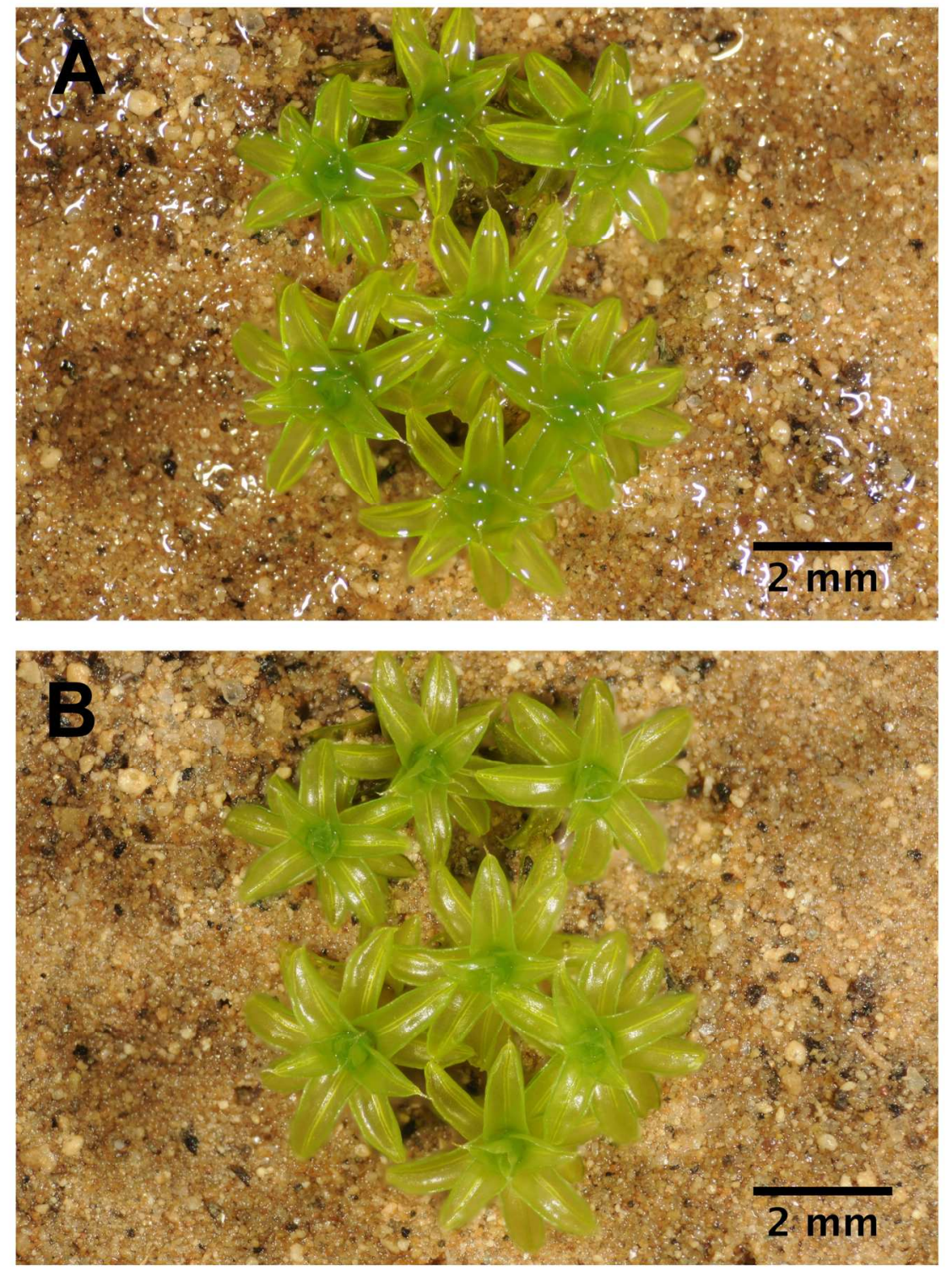

Figure 01

$165 \times 222 \mathrm{~mm}(300 \times 300 \mathrm{DPI})$ 


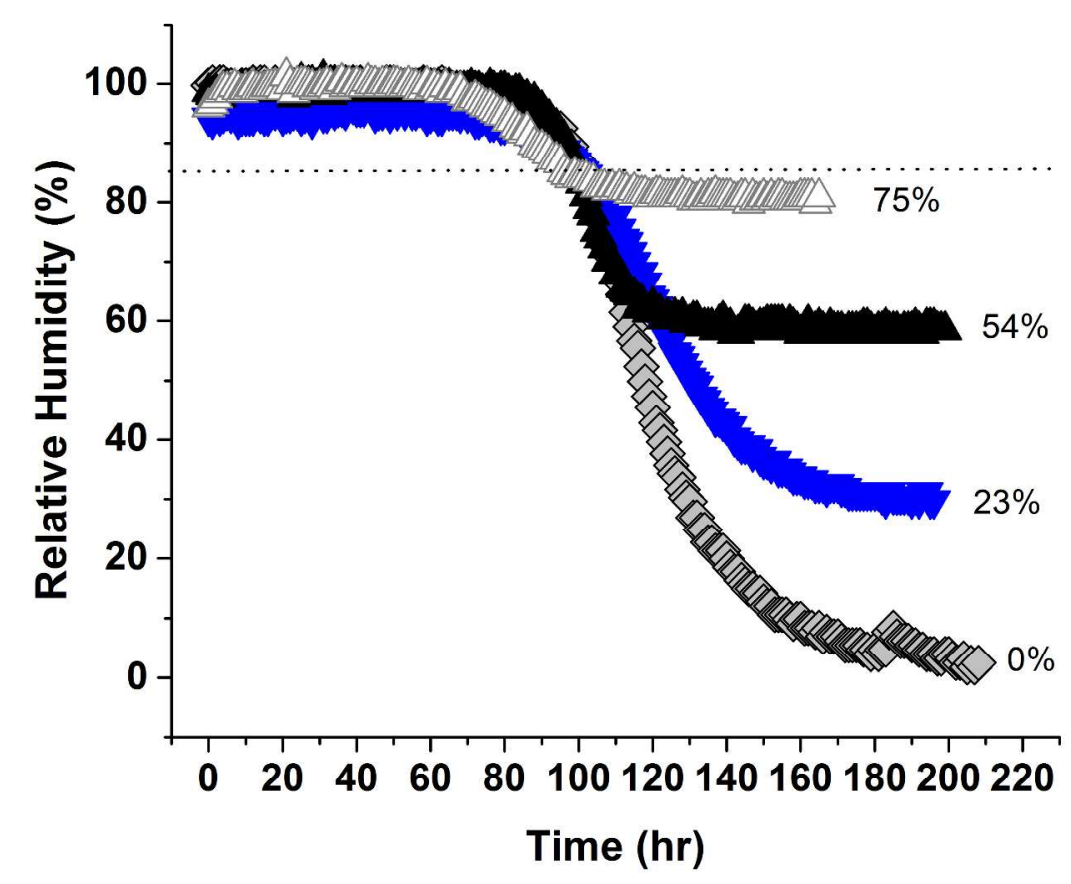

Figure 02

$274 \times 209 \mathrm{~mm}(300 \times 300$ DPI $)$ 

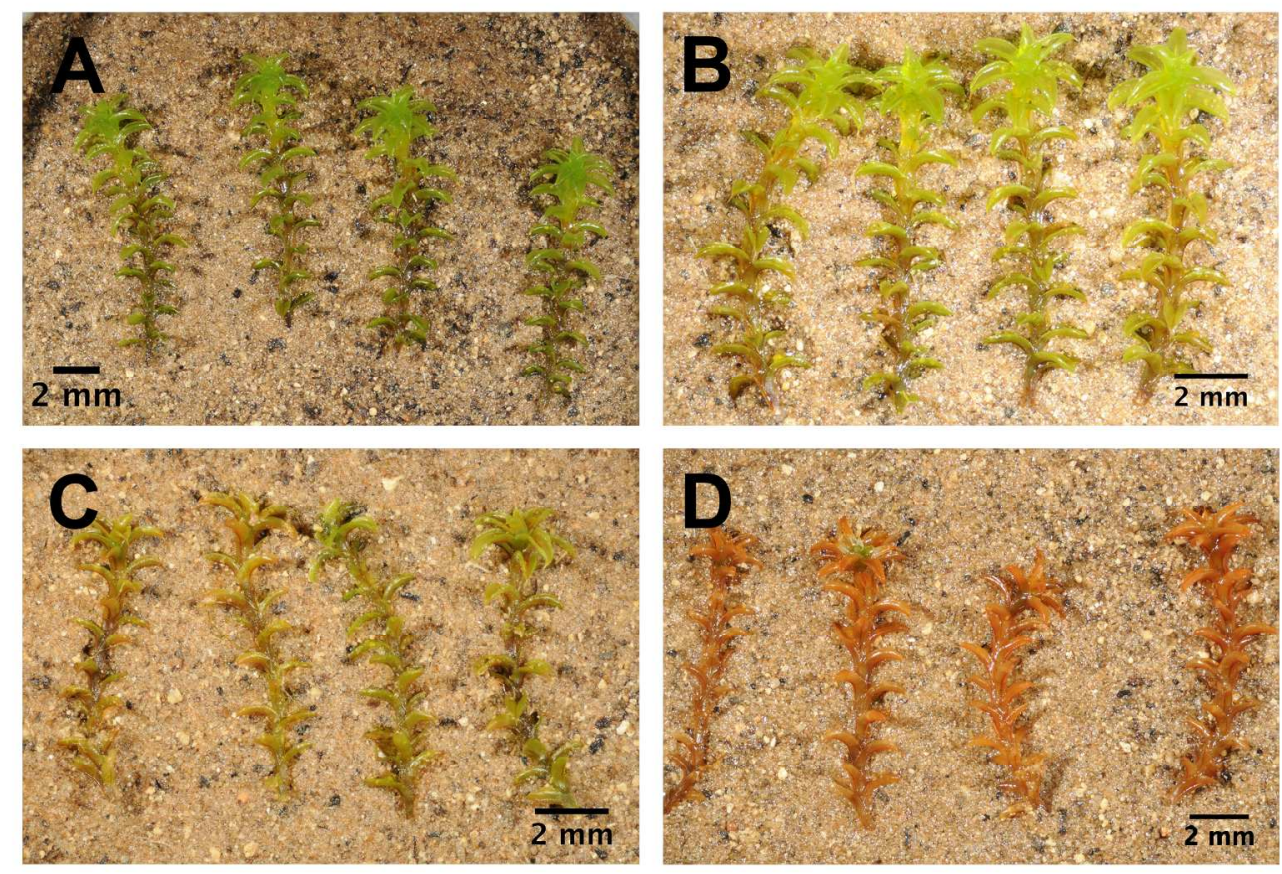

Figure 03

$215 \times 149 \mathrm{~mm}(300 \times 300$ DPI $)$ 


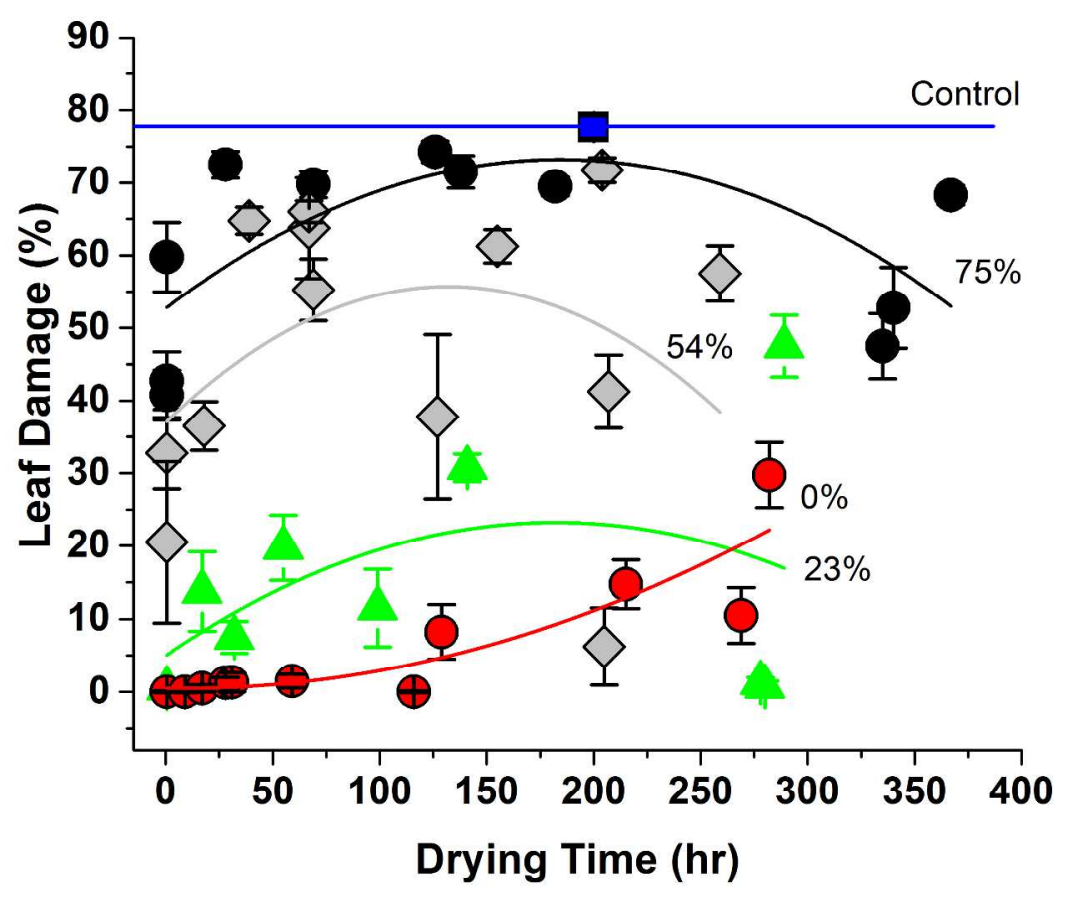

Figure 04

$274 \times 209 \mathrm{~mm}(300 \times 300$ DPI $)$ 

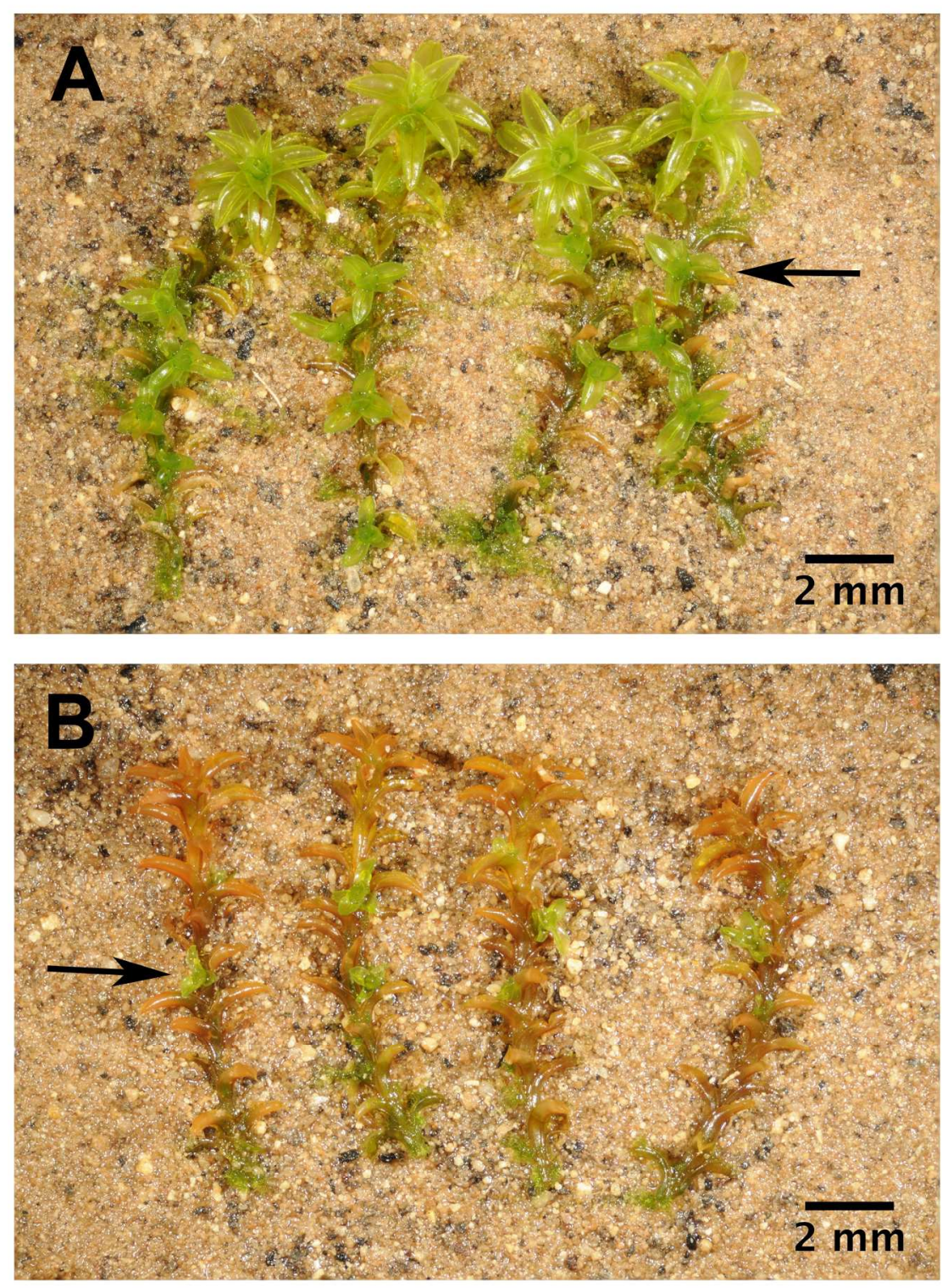

Figure 05

$165 \times 222 \mathrm{~mm}(300 \times 300$ DPI $)$ 


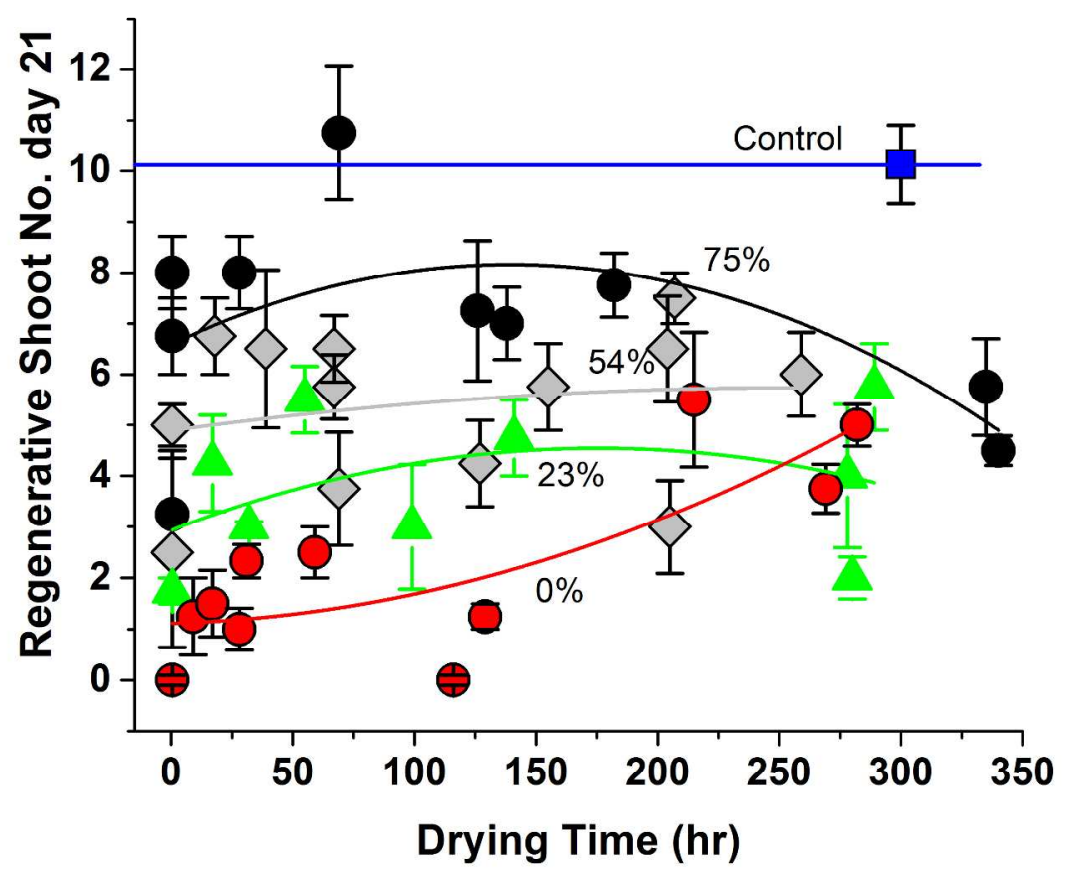

Figure 06

$274 \times 209 \mathrm{~mm}(300 \times 300$ DPI $)$ 


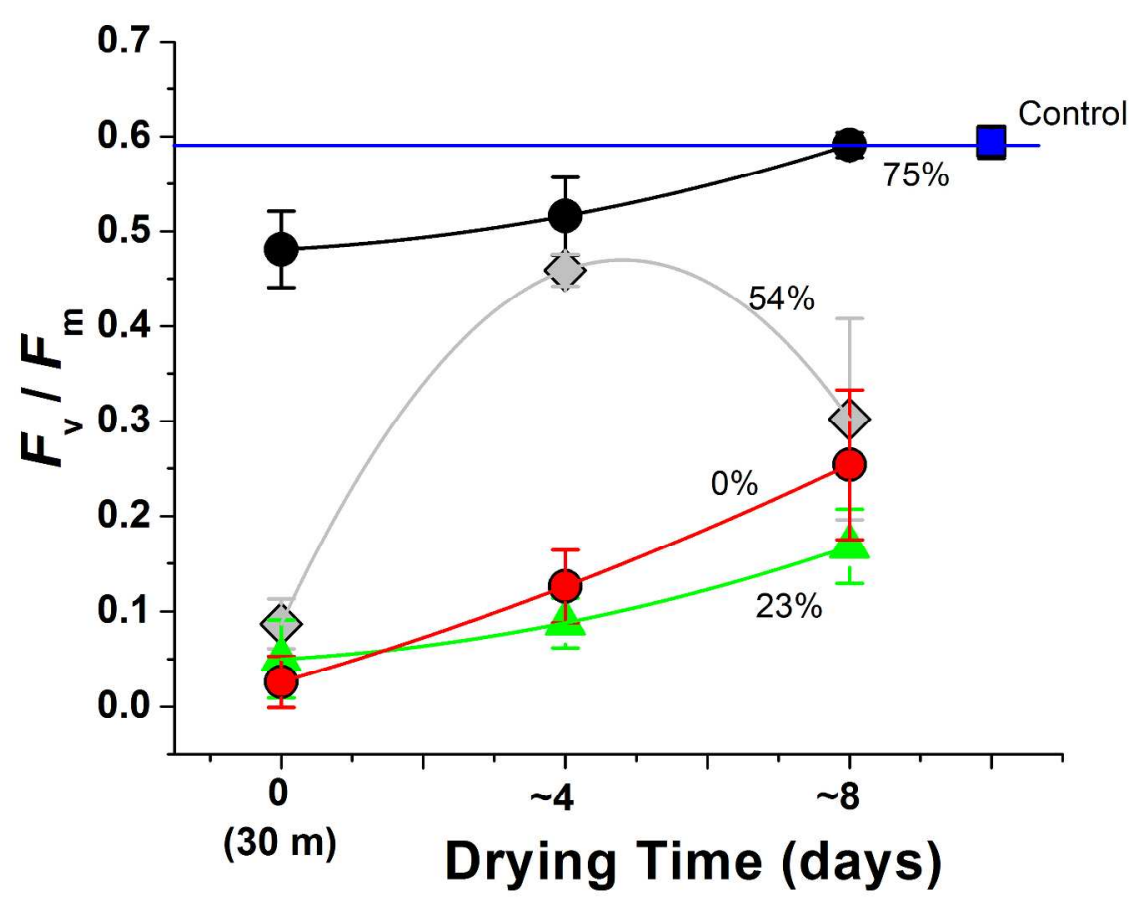

Figure 07

$274 \times 209 \mathrm{~mm}(300 \times 300$ DPI $)$ 


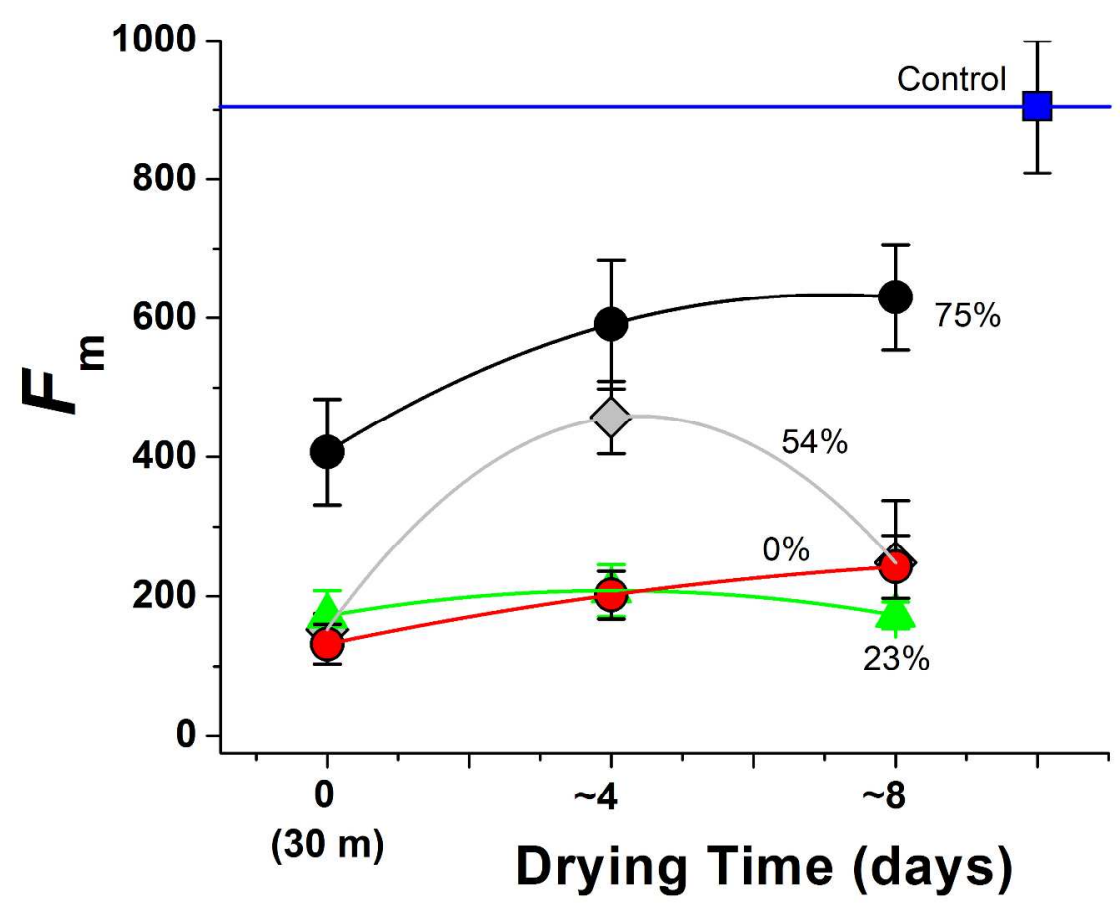

Figure 08

$274 \times 209 \mathrm{~mm}(300 \times 300$ DPI $)$ 


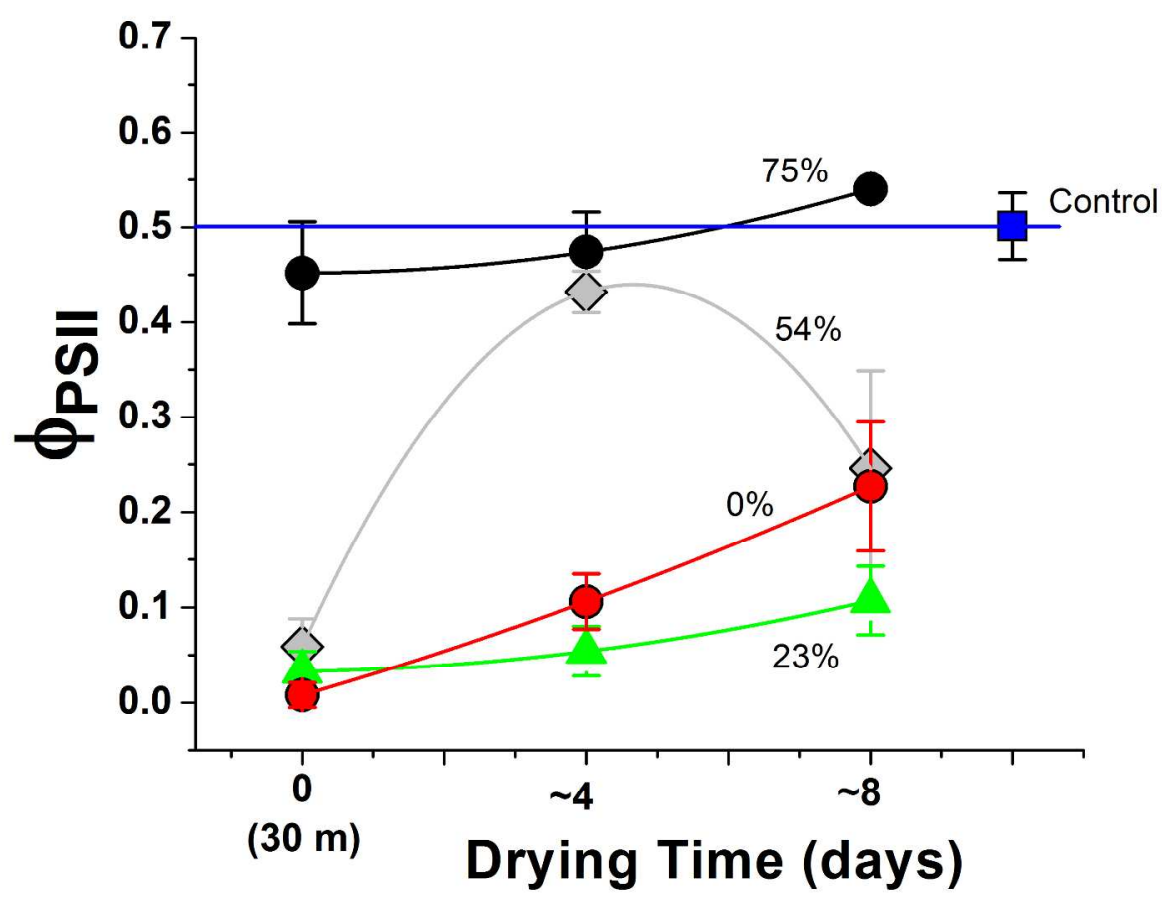

Figure 09

$274 \times 209 \mathrm{~mm}(300 \times 300$ DPI) 